\title{
The influence of carbohydrases on the growth of fungal pathogens in vitro and in vivo
}

\author{
A. M. S. POPE* \\ Ph.D. \\ D. A. L. DAVIES \\ Ph.D., D.Sc., Sc.D., F.I.Biol. \\ * Searle Research Laboratories, Lane End Road, High Wycombe, Buckinghamshire
}

\begin{abstract}
Summary
Mixtures of mycolytic enzymes from various sources release protoplasts from living fungal tissue under suitable conditions. Such enzyme mixtures obtained from Coprinus comatus (mycolase I), Physarum polycephalum (mycolase II) and Lycoperdon pyriforme (mycolase III) are of low toxicity in mammals when given parenterally and are able to cure experimental systemic fungal infections in mice when administered alone or in conjunction with normally ineffective levels of conventional antimycotic drugs such as amphotericin B. The effect is believed to be due to enzymic degradation of the fungal cell wall either killing the fungus directly or enhancing activity of existing antifungal agents by increasing access to the cell interior.
\end{abstract}

\section{Introduction}

Fungal infections are a major cause of morbidity and mortality throughout the world (Ajello, 1971; Mycoses, 1975) and patients under induced immunosuppression for organ transplantation or receiving chemotherapy for cancer are susceptible to disease caused by 'opportunistic' organisms such as Aspergillus and Candida spp. (Bodey, 1977; Mason et al., 1976). In spite of increasing awareness of the importance of fungal infections, there is a shortage of effective antimycotic agents and those that are available have drawbacks that limit their usefulness. Amphotericin B has been the drug of choice for treatment of systemic fungal disease, but it is nephrotoxic and has other undesirable side effects (Bennett, 1974). Flucytosine is less toxic than amphotericin but emergent fungal resistance to this drug is a potentially serious problem (Utz, 1977). Newer antifungal agents such as miconazole and clotrimazole are still being evaluated.

The essence of effective chemotherapy is to exploit differences between host and pathogen so that the host is unaffected by the treatment. In fungal infections, exploitable differences are few because both host and pathogen are eukaryotes. However, an obvious difference between fungal and mammalian cells that has not been exploited is the presence in fungi of a polysaccharide cell wall that frequently contains chitin (Bartnicki-Garcia, 1968). The cell wall can also be seen as a barrier to effective chemotherapy. Certainly, Gale et al. (1975) have shown that protoplasts of $C$. albicans are more sensitive to amphotericin $B$ than are intact cells. The novel approach to antimycotic therapy described in this communication exploits the cell wall by making chitin and other polysaccharides the target for enzymatic attack. Damage to or removal of the cell wall should either kill the fungus directly or, at least, enhance the activity of existing drugs by increasing their access to the cell interior. Experiments intended to test this hypothesis are described below.

Materials and methods

Organisms and media

$A$. fumigatus and $C$. albicans were obtained from the Searle culture collection. Physarum polycephalum (strain i x a7029) was obtained from Dr M. J Carlile, Department of Biochemistry, ImperiasCollege of Science and Technology, Prince Consort Road, London, S.W.7. Specimens of Coprinus comatus and Lycoperdon pyriforme were collected in the Chiltern beechwoods around High Wycombe and stored at $-20^{\circ} \mathrm{C}$ until required.

$A$. fumigatus and Candida albicans were grown on glucose peptone medium containing (per litre) glucose $10 \mathrm{~g}$, peptone $2 \mathrm{~g}, \mathrm{KH}_{2} \mathrm{PO}_{4} 0.5 \mathrm{~g}, \mathrm{MgSO}_{4}$ $0.5 \mathrm{~g}$. Universal bottles containing $10 \mathrm{ml}$ of this medium were inoculated with a spore suspension of $A$. fumigatus and incubated for $20 \mathrm{hr}$ at $24^{\circ} \mathrm{C}$ on a Luckham Rolamix blender. $P$. polycephalum was grown on the medium described by Carlile (1971).

\section{Enzyme preparation}

Enzyme mixtures were obtained from fresh or frozen specimens of Coprinus comatus and L. pyriforme either by allowing the fruit bodies to autolyse at $4^{\circ} \mathrm{C}$ in sterile containers for $24-48 \mathrm{~h}$ or by homogenizing fruit bodies in a Waring Blender for $5 \mathrm{~min}$ at $4^{\circ} \mathrm{C}$. The homogenates obtained were expressed through muslin and the remaining solid discarded. The fluid was then centrifuged in sterile containers at $3000 \mathrm{~g}$ for $15 \mathrm{~min}$ and the pellet discarded. The supernatant contained the crude enzyme mixture which was then lyophilized. 
A 'purified' extract of $L$. pyriforme was prepared by fractionating the crude enzyme mixture on Bio-Gel P200 (Bio-Rad Laboratories, Richmond, California) and recombining the retarded fractions.

A mixture of mycolytic enzymes was obtained from culture supernatants of $P$. polycephalum as follows: Cellular material was removed by centrifugation at $1600 \mathrm{~g}$ for $15 \mathrm{~min}$ at $4^{\circ} \mathrm{C}$ and viscous polysaccharide precipitated from the supernatant by adding one volume of cold $\left(-20^{\circ} \mathrm{C}\right) 95 \%$ ethanol and centrifuging at $10000 \mathrm{~g}$ for $30 \mathrm{~min}$ at $4^{\circ} \mathrm{C}$ to sediment the resultant precipitate. The clear supernatant was dialysed against water to remove the ethanol and lyophilized.

Chitinase (E.C. 3.2.11.4.) was obtained from Koch Light Laboratories, Colnbrook, Buckinghamshire, and laminarinase $(\beta-1,3(4)$ glucan glucanohydrolase E.C. 3.2.1.6.) was obtained from Calbiochem, San Diego, California.

\section{Protoplast assay}

This was carried out according to the method of Bartnicki-Garcia and Lippmab (1966) using molar $\mathrm{MgSO}_{4}$ as an osmotic stabilizer. A. fumigatus was the target organism and all enzymes were at a final concentration of $240 \mathrm{mg} / \mathrm{l}$.

\section{Experimental infection}

Groups of 5 or 10 female BALB/c mice weighing 22-25 $\mathrm{g}$ were infected by intravenous injection with either $5 \times 10^{6}$ spores of $A$. fumigatus or $25 \times 10^{4}$ blastospores of $C$. albicans in saline. On one or more of the days following infection, animals were treated intraperitoneally with enzymes, conventional antimycotic drugs or combinations of the two. Treatments were given in $0.2 \mathrm{ml}$ of $5 \%$ dextrose or water for injection.

TABle 1. Production of protoplasts from Aspergillus fumigatus

\begin{tabular}{ll}
\hline \multicolumn{1}{c}{ Enzyme treatment } & $\begin{array}{c}\text { Protoplast } \\
\text { release }\end{array}$ \\
\hline Chitinase & + \\
$\beta-1,3$-glucanase & - \\
Chitinase $+\beta-1,3$-glucanase & ++ \\
$\begin{array}{l}\text { Coprinus } \text { extract }- \text { mycolase I } \\
\text { Physarum culture SN }- \text { mycolase II }\end{array}$ & +++ \\
Lycoperdon extract - mycolase III & +++++ \\
\hline & + Protoplasts from hyphal tips only. \\
++ Protoplasts from tips and intercalary com- & partments. \\
+++ Many protoplasts released throughout my- \\
$\quad$ celium.
\end{tabular}

\section{Results}

Results for protoplast release from $A$. fumigatus are given in Table 1. Chitinase released protoplasts only from hyphal tips, whereas $\beta-1,3$-glucanase did not liberate any protoplasts. A mixture $(1: 1$ by weight) of the 2 enzymes was more effective than either component alone. Mycolases I, II and III (from Coprinus comatus, $P$. polycephalum and $L$. pyriforme respectively) were more effective than the commercial enzyme mixture, and treatment with mycolase II resulted in complete lysis of the target mycelium. Similar results have been obtained with $C$. albicans and a range of microfungi (Pope and Davies, unpublished data).

Results in Table 2 show that infected, untreated mice had a mean survival time of 13.5 days (Table $2 \mathrm{a}$. Under the conditions of the test, a single treatment with the maximal sub-toxic dose of amphotericin B or nystatin significantly prolonged survival, but did not cure the animals (Table $2 \mathrm{k}, \mathrm{m}$ ). Animals were cured by mycolases alone (Table 2 $d, j$ ) but not by the commercial enzyme mixture (Table 2 b). Infections were also cured by the synergistic effect of mycolases and conventional antifungal agents at doses of both components that were ineffective when administered alone (Table $2 \mathrm{o}, \mathrm{p}$, $q, r, s)$. Mice that had been immunosuppressed with rabbit anti-mouse thymocyte globulin (ATG) were also cured by combined therapy, suggesting that a full immune capacity is not an essential prerequisite for the effect. Similar results have been obtained in experimental candidiasis and in the treatment of dermatophyte infection in guinea-pigs (Pope and Davies, unpublished data).

Acute toxicity tests with mycolases given intravenously or intraperitoneally in mice gave an $\mathrm{LD}_{50}$ of $15-20 \mathrm{mg} / \mathrm{mouse}(600-700 \mathrm{mg} / \mathrm{kg})$.

\section{Discussion}

The fungal cell wall has been recognized by other workers as a potential target for therapeutic attack. Specific inhibitors of chitin synthetase, the polyoxins, have been developed (Endo, Kakiki and Misato, 1970), but although these compounds are effective in vitro, they have not proved useful clinically. Chitinases occur widely in nature (Stirling, Cook and Pope, 1979) and, although their effects on fungal cell walls in vitro, alone and in conjunction with other enzymes are well known, as far as the authors are aware there have been no in vivo studies. Miura (1954) suggested that chitinase might be used for treating dermatophyte infections, but did not demonstrate mycocidal activity. The results show that chitinase alone is only slightly mycolytic and requires the presence of other enzymes before its full potential can be realized. The increased mycolytic activity of mycolases compared with the commercial enzyme mixture is almost certainly attributable to the wider range of carbohydrases they contain. Enzyme profiles for mycolases will be published elsewhere. 
TABLE 2. Fate of BALB/c mice infected systemically with Aspergillus fumigatus

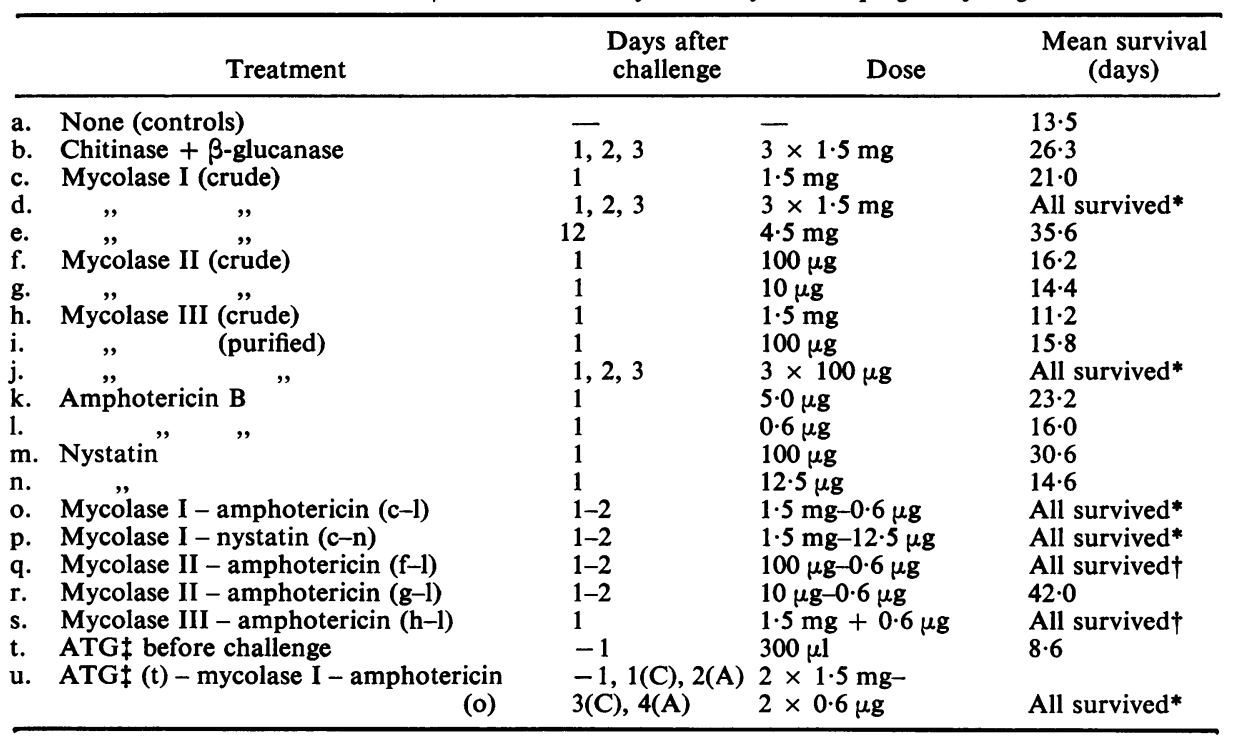

* Significantly different from a at the $1 \%$ level.

+ Significantly different from a, $f$ and $j$ at the $1 \%$ level. (Logrank $\chi^{2}$ analysis, Peto and Pike, 1973).

¥ ATG is rabbit anti-mouse thymocyte globulin. $300 \mu \mathrm{l}$, injected subcutaneously, was the amount able to prolong the survival of allogeneic skin grafts from 8-10 days to 25-35 days.

Mycolases have been shown to be effective in both immune competent and immunosuppressed animals alone and in combination with existing antimycotic drugs (Davies and Pope, 1978). The latter approach allows reduction in drug dosage and associated toxicity. In vitro tests suggest that addition of mycolase gives a 5- to 10-fold reduction in the MIC of a range of antifungal drugs. This is probably due to the increased access to the cell interior through the enzyme-damaged walls.

Mycolases have a wide spectrum of antifungal activity, are of low toxicity and there would seem to be only a remote chance of fungi developing resistance to their attack. The authors believe that mycolases hold considerable promise as an alternative to existing therapy for both systemic and superficial fungal infections.

\section{References}

AJELLO, L. (1971) The medical mycological iceberg. HSMHA Health Reports, 86, 437.

BARTNICKI-GARCIA, S. (1968) Cell wall chemistry, morphogenesis and taxonomy of fungi. Annual Review of Microbiology, 22, 87.

BARTNICKI-GARCIA, S. \& LipPMAN, E. (1966) Liberation of protoplasts from the mycelium of Phytophthora. Journal of General Microbiology, 42, 411.

BENNETT, J.E. (1974) Chemotherapy of systemic mycoses New England Journal of Medicine, 290, 30.
BoDEY, G.P. (1977) Fungal infections in the cancer patiento South African Medical Journal, 52, 1009.

Carlile, M.J. (1971) Myxomycetes and other slime moulds Methods in Microbiology, 4, 237.

DAvies, D.A.L. \& Pope, A.M.S. (1978) Mycolase, a new kin开 of systemic antimycotic. Nature. London, 273, 235.

Endo, A., KaKIKI, K. \& Misato, T. (1970) Mechanism of action of the antifungal agent polyoxin D. Journal of Bacteriology, 104, 189.

Gale, E.F., Johnson, A.M., Kerridge, D. \& KoH, T.Y. (1975) Factors affecting the changes in amphotericin B sensitivity of Candida albicans during growth. Journal of General Microbiology, 87, 20.

Mason, J.W., Stinson, E.B., Hunt, S.A., Schroeder, J.S. \& RIDER, A.K. (1976) Infections after cardiac transplantation: Relation to rejection therapy. Annals of Internal Medicine, 85, 69.

MiURA, O. (1954) Utilization of chitinase in the treatment of dermatomycosis. I. Influence of Bacillus chitinovori on the culture of dermatophytes. Tohoku Journal of Experimental Medicine, 59, 403.

Mycoses (1975) Proceedings of the 3rd International Conference on Mycoses. Scientific Publication 304. PanAmerican Health Association.

Peto, R. \& Pike, M.C. (1973) Conservation of the approximation (O-E) ${ }^{2} / \mathrm{E}$ in the logrank test for survival data on tumour incidence data. Biometrics, 29, 579.

StiRling, J.L., Cook, G.A. \& PoPE, A.M.S. (1979) Chitin N and its degradation. In: Symposium on Wall and Hyphal Growth. (In press.)

UTz, J.P. (1977) The current status of chemotherapeutic agents for the systemic mycoses. Contributions to Microbiology and Immunology, 4, 124. 